\title{
Standards of (In)coherence in Ancient Jewish Literature ${ }^{1}$
}

\author{
Andrew Teeter and William Tooman
}

\section{Part 1. 'Coherence' and 'Unity'}

\subsection{What is coherence?}

Coherence-whether understood narrowly as compatibility between constituents of a textual world, or quite broadly as a regulative principle applying to all areas of text production and reception - is a constitutive feature of textuality. ${ }^{2}$ While there is much disagreement about the concept, all agree that "coherence" is a fundamental ingredient of a "text" as such —or at least of its meaningful experience. It is an expectation brought to anything that might be considered a 'text,' though it is not found in equal measure in every text. ${ }^{3}$ The degree and kind of coherence expected of a text (and the effort exerted to satisfy such expectations) depend on a variety of factors. ${ }^{4}$

This article sketches an anatomy of issues representing key points of debate, differences in approach, and decisions that must be made in the attempt to understand coherence and incoherence in ancient Jewish literature. One of several key difficulties in assessing the

${ }^{1}$ For the purposes of this essay, we are using 'ancient Jewish literature' as catch-all for the literatures of ancient Israel and ancient Judaism before the Mishna.

2 "[W] consider a text to be a monological stretch of written language that shows coherence" (T. Sanders and J. Sanders, "Text and Text Analysis," in Encyclopedia of Language and Linguistics [ed. K. Brown; $2^{\text {nd }}$ ed.; Amsterdam: Elsevier, 2006], 597-607 at 598). For coherence as a "regulative principle," see K. Adamzik, Textlinguistik: Eine einführende Darstellung (Niemeyer: Tübingen, 2004), 58-59; and consider, by contrast, the discussion of regulative and constitutive principles in R. de Beaugrande and W. Dressler, Introduction to Text Linguistics (London: Longman, 1981), 11. The latter relate coherence to the "ways in which the components of the TEXTUAL WORLD, i.e. the configuration of CONCEPTS and RELATIONS which underlie the surface text, are mutually accessible and relevant" (4). "In general, by coherence is meant that the constituents of a unit will be semantically compatible with each other" (J. Beekman, J. Callow, and M. Kopesec, The Semantic Structure of Written Communication ( $5^{\text {th }}$ ed.; Dallas: SIL International, 1981) 21. The latter further specify referential coherence, structural coherence, and situational coherence, which includes emotive, tonal, or connotational coherence.

${ }^{3}$ E. Blum: "Kohärenz ist prinzipiell gegeben, sofern eine sprachliche Größe als Text rezipiert wird. Die Fragestellung, $o b$ ein Text Kohärenz aufweist, wäre mithin widersinnig. Vielmehr kann es grundsätzlich nur darum gehen, von welcher Art und welcher intensität die Kohärenz auf den verschiedenen Textebenen ist. [Mit „Textebenen“ sind hier einerseits Syntax, Semantik und Pragmatik gemeint, andererseits die Oberflächenstruktur und Tiefenstruktur der Texte].” ("Von Sinn und Nutzen der Kategorie „Synchronie“ in der Exegese,” in Grundfragen der historischen Exegese [ed. W. Oswald and K. Weingart; FAT 95; Tübingen: Mohr Siebeck, 2015], 55-68, at 67). De Beaugrande and Dressler: "To some degree, cohesion and coherence could themselves be regarded as operational goals without whose attainment other discourse goals may be blocked. However, text users normally exercise TOLERANCE towards products whose conditions of occurrence make it hard to uphold cohesion and coherence altogether...notably in casual conversation" (Introduction to Text Linguistics, 7). Cf. Adamzik: "Es gibt denn doch eine gewisse Toleranz gegenüber inhaltlich nur schwach (oder auch gar nicht) verknüpften Teiltexten, und Sprachbenutzer rechnen mit unterschiedlich ausgeprägter Kohärenz auch bei Gebrauchstexten" (Textlinguistik, 128-29).

${ }^{4}$ This includes, not least, the type of text under consideration See, e.g., A. Samely with P. Alexander, R. Bernasconi, and R. Hayward, Profiling Jewish Literature in Antiquity: An Inventory from Second Temple Texts to the Talmuds (Oxford: Oxford University Press, 2013), 23; M. Heath, Unity in Greek Poetics (Oxford: Clarendon, 1989), 1. 
problem of "coherence" (or its absence) in the Hebrew Bible and ancient Jewish literature concerns the fact, just mentioned, that the definition of "coherence" is itself contested, both in biblical studies and in other disciplines. ${ }^{5}$ Within text-linguistic research, for example, the concept of "coherence" has been understood in a wide variety of ways and with diverse applications, ranging from the very narrow (closely approximating the notion of grammatical and lexical cohesion) ${ }^{6}$ to the very broad ("coherence" as a comprehensive category of understanding that applies to all essential aspects of a text). ${ }^{7}$ Differences in the scope of the concept tend to yield quite different descriptions and conclusions.

On this question of definition also turns the debated issue of the locus of coherence: internal ("intra-," "inner-," and "inter-textual") and/or external ("extra-textual"). ${ }^{8}$ Put as a question, is coherence properly a feature inherent to texts, or is it a property granted to it by readers? Outside of linguistic research, the former conclusion is disputed. The latter is not. This dispute requires some clarification.

In the first place, there are limitations peculiar to written communication that require readers to participate in coherence construction. The principle of selection by which writers choose which events and things to pronounce and which to imply accounts for the fundamentally gapped quality of all writing. Rendering a complete account is impossible. ${ }^{9}$ One could describe, in endless detail, the features of a character or object or the contours of an event

${ }^{5}$ On the lack of terminological clarity in biblical studies, see M. Z. Brettler, "The 'Coherence' of Ancient Texts," in Gazing on the Deep: Ancient Near Eastern and Other Studies in Honor of Tzvi Abusch (ed. J. Stackert et al; Bethesda: CDL, 2010), 411-419 at 412.

${ }^{6}$ M.A.K. Halliday and R. Hassan, Cohesion in English (London: Longman, 1976).

${ }^{7}$ For the broad view, see esp. K. Brinker, Linguistische Textanalyse: Eine Einführung in Grundbegriffe und Methoden ( $5^{\text {th }}$ ed.; Grundlagen der Germanistik 29; Erich Schmidt: Berlin, 2001), 18, and Adamzik, Textlinguistik, who understand coherence "as a comprehensive concept that incorporates both linguistic and conceptual, as well as functional and even situational aspects - that is, in and between the individual dimensions one must always examine to what extent coherence is present and how it is constituted or how it is disturbed. I regard it as a break in coherence even when expressions that are conceptually quite compatible are juxtaposed in a conflicting stylistic register; if the theme or even a specific expression does not fit the situation. [...] I do not regard coherence, therefore, as an independent dimension, but rather as a 'regulative principle' of text production and text reception" (Textlinguistik, 58). "The question of to what degree coherence is present must be examined/decided not only for the cohesively (dis-)connected linguistic signs and with reference to the dimensions of situation, theme, and function; rather, coherence (or the rupture of coherence) can also be present between the various dimensions..." (Textlinguistik, 59). See also G. Fritz, Kohärenz: Grundfragen der linguistischen Kommunikationsanalyse (TBL 164; Tübingen: Narr, 1982), 1-12 (esp. 10); J. Petöfi, “Theoretische Forschung. Aspekte der Textkohärenz, Sprachunterricht”, in Text, Kontext, Interpretation (ed. K. DorfmüllerKarpusa and J. Petöfi; Hamburg: Buske, 1981), 235-85, at 236. For mediating views, see de Beaugrande and Dressler (n. 1 above); W.-D. Krause, Textsorten: Kommunikationslinguistische und konfrontative Aspekte (SST 33; Frankfurt am Main: Peter Lang, 2000), for whom coherence is "the expression of a conceptual connection, primarily grounded thematically, between propositions expressed in language. This connection is naturally related to the meaning of a text and therefore to problems of understanding, but it is not thereby identical to those..." (57); and others discussed in Adamzik, Textlinguistik, 55.

${ }^{8}$ See Adamzik, Textlinguistik, 54-59; de Beaugrande and Dressler, Introduction, 6-7; Krause, Textsorten, 49-52, 58; cf. C. J. Fillmore, "Linguistics as a Tool for Discourse Analysis," in Handbook of Discourse Analysis: Vol I: Disciplines of Discourse (ed. T. A. van Dijk; London: Academic, 1985), 11-39 at 11.

${ }^{9} \mathrm{R}$. Ingarden describes this as the fundamental limitation of written communication (Der Streit um die Existenz der Welt, vol. II/1 (Tubingen: Max Niemeyer, 1968), 220; see also at n.12 below. W. Iser stresses that gaps not only pose challenges to understanding, they are also the basic inducement to communication (The Act of Reading, 166-67; 183-84). On all the issues discussed here see L. Doležel, "Possible Worlds and Literary Fictions," in Possible Worlds in Humanities, Arts, and Sciences (ed. A. Sture; Research in Text Theory 14; Berlin: de Gruyter, 1988), 221-42 and, especially, Wolfgang Iser, "Indeterminacy and the Reader's Response in Prose Fiction," in Aspects of Narrative, English Institute Essays (ed. by J. Hillis Miller; New York: Columbia University Press, 1971), 1-45. 
or argument without achieving a complete description without gaps and blanks. The "involvement of the reader or spectator as accomplices or collaborators is essential in the curious situation of artistic communication." 10 Gap-filling is one of the ways that readers continually (often unconsciously) contribute to the coherence of the communications that they receive. It is the responsibility of readers to fill many of those gaps, a tacit responsibility neither offered nor demanded in any explicit way. Fulfilling that responsibility is a powerful act of coherence-building. ${ }^{11}$

The contributions that readers make to a text's coherence seem innumerable both in frequency and kind. For example, in Genesis $12.4-5$ we read: " ${ }^{4} \mathrm{Abram}$ went, just as YHWH told him, and Lot went with him. Abram was seventy-five years old when he departed Haran. ${ }^{5}$ Abram took his wife Sarai and his nephew Lot, and all the stuff that they had gathered, and the persons whom they had acquired in Haran, and they set out to go to the land of Canaan." Persons and things in the story ('existents') are assumed to persist. The 'Lot' of verse 4 is the same person specified in verse 5 as "his brother's son," or so one naturally assumes. Were the two persons different characters, one would expect the writers would have revealed it in some way. Absent such a revelation, the reader grants continuity of identity to the existent 'Lot.' The same applies to 'Abram,' 'Sarai,' and 'Haran'; all three having been introduced at the end of chap 11. Another common type of reader contribution is 'event causality.' Again, we read in Gen 16.6: 'Abram said to Sarai, 'Your slave-girl is in your power; do to her as you please,' so Sarai was cruel to her, and she ran away from her." It is natural to assume that Hagar ran away because of Sarah's treatment of her. The writers neither imply nor say as much. It is assumed that the juxtaposition of clauses is a sufficient indicator. ${ }^{12}$ Of course, some readers are more aware of their own contributions to the reading process than others. Academic readers, in particular, are trained to observe gaps and blanks and to restrain the impulse to fill them too quickly. ${ }^{13}$ Good reading calls for such restraint, since good writers will exploit readerly impulses. Even good readers can stumble, though. A cultivated restraint can become a reading flaw if exercised stubbornly, erratically, or in a historically inappropriate way. ${ }^{14}$

${ }^{10}$ L. Nelson Jr., "The Fictive Reader and Literary Self-Reflectiveness," in The Disciplines of Criticism: Essays on Literary Theory, Interpretation, and History, Honoring René Welek on the Occasion of his Sixty-fifth Birthday (eds. P. Demetz, T. Green, and L. Nelson, Jr.; New Haven: Yale University Press, 1968), 174.

${ }^{11} \mathrm{~S}$. Chatman describes a 'story' as "the continuum of events presupposing the total set of all conceivable details" (Story and Discourse: Narrative Structure in Fiction and Film [Ithaca and New York: Cornell University Press, 1978], 28). Iser makes the same point about all texts: "By grouping together the written parts of the text, we enable them to interact, we observe the direction in which they are leading us, and we project onto them the consistency which we, as readers, require. This 'gestalt' must inevitably be colored by our own characteristic selection process. For it is not given by the text itself; it arises from the meeting between the written text and the individual mind of the reader with its own particular history of experience, its own consciousness, its own outlook" ("The Reading Process: A Phenomenological Approach," New Literary History 3/2 [1972]: 289). In their conception, the 'story' is a composite of written and imagined elements and therefore is never the same twice. This is one of the unique pleasures of rereading.

${ }^{12}$ Ingarden refers to any lack of identicality between the contours of a work and its realization by the reader as "places of indeterminacy" (The Literary Work of Art [Evanston, IL: Northwestern University Press, 1973], 2930, 267, 332-6, etc.). Iser builds on Ingarden's observation, exploring how gap-filling is not only an act of completion but of combination. "It is only when the schemata of the text are related to one another that the imaginary object can begin to be formed, and it is the blanks that get this connecting operation under way" (Act of Reading, 183-86 quote at 183).

13 This is one facet of Ingarden's 'aesthetic experience,' which is to be distinguished from 'mere looking' or 'mere reading' (“Artistic \& Aethetic Values,” British Journal of Aesthetics 4/3 [1964], 198-213).

${ }^{14}$ In one recent study on "Pentateuchal Coherence," Jeffery Stackert proposed that Exod 4.2 and 17 represent "contradictory narrative claims." According to Stackert, in 4.2 "Moses possesses a rod that Yahweh then instructs him to use," whereas in 4.17 "the deity gives such a rod to Moses, implying that Moses did not possess a rod previously." Stackert assumes the persistence of the existents 'Moses' and 'YHWH' but, in an act of 
Granting all this, an over-emphasis on coherence as a contribution of readers is liable to promote a serious misunderstanding. On the one hand, coherence clearly relates to mental processes impossible apart from the active involvement of readers. From this standpoint, a reader seeks out and thereby constitutes coherence. ${ }^{15}$ On the other hand, these mental processes are bound to the physical text as a functional whole that represents the embodiment of an intentional, situational, communicative act, a strategy of communication manifested in tightly related features (cohesion, structure, boundedness, referentiality, etc). From this standpoint, a reader finds or re-creates the coherence encoded within the text. A reader does not create it de novo. ${ }^{16}$

Coherence, then, requires cooperation between text producers and consumers. ${ }^{17}$ It is a communicative transaction that assumes and requires the participation of writers and readers and is delivered in the form of an aural or physical object (the text). So, although coherence is a "text-notion," it is "not a mere feature of texts, but rather the outcome of cognitive processes

restraint, does not do so for the staff. Then, eschewing restraint, he perceives and fills gaps in 4.17: "take in your hand this [brand new] staff [since you lack one]." ("Pentateuchal Coherence and the Science of Reading," in The Formation of the Pentateuch: Bridging the Academic Cultures of Europe, Israel, and North America (ed. J. Gertz et al; FAT 111; Tübingen: Mohr Siebeck, 2016), 253-68, at 257). Stackert's broader goal is to "apply the findings of empirical research on reading comprehension, textual cohesion and coherence, and cognition especially in the fields of psychology, linguistics, and education to the question of how readers understand pentateuchal texts as unified and coherent" (ibid., 253-54). On the limitations of empirical reading-research for understanding bona fide literature as opposed to small 'textoids,' see A. Grosser, M. Gernsbacher, and S. Goldman, "Cognition," in Discourse as Structure and Process, vol 1 (ed. T. van Dijk; London, Thousand Oaks, and New Delhi: Sage, 1997), 292-319, esp. 312-13; A. Samely, "Jewish Studies and Reading," in 'Let the Wise Listen and Add to Their Learning'. Festschrift for Günter Stemberger on the Occasion of his 75th Birthday (eds. G. Langer and C. Cordoni; Berlin: de Gruyter, 2016), 767-771; J. Petöfi, "Towards an Empirically Motivated Grammatical Theory of Verbal Texts," in Studies in Text Grammar (eds. J. Petöfi and Hannes Reiser; Dordrecht and Boston: Reidel, 1973), 205-275; H. van Oostendorp and R. A. Zwaan, Naturalistic Text Comprehension (Norwood NJ: Ablex, 1994).

15 “... kommen wir zu dem Ergebnis, dass ... die Kohärenzherstellung auch eine vom Rezipienten zu leistende Aufgabe ist: er sucht und stiftet selbst Zusammenhänge” (Adamzik, Textlinguistik, 128-29). "Coherence is considered a mental phenomenon; it is not an inherent property of a text under consideration" (Sanders and Sanders, "Text and Text Analysis," 599). "[T]he dominant view has come to be that the connectedness of discourse is a characteristic of the mental representation of the text rather than of the text itself. The connectedness thus conceived is often called coherence" (ibid., 592). "... coherence is something that the reader creates in dialogue with the text - it is 'a mental phenomenon'" (Brettler, "The 'Coherence' of Ancient Texts, 414 with embedded quote from Gernsbacher and Givón, "Introduction: Coherence as a Mental Entity," in Coherence in Spontaneous Text [ed. Gernsbacher and Givón; Philadelphia: J. Benjamins, 1995], vii). Coherence "is properly an achievement of the reader, even as it is highly dependent on a text's cohesive ties." (Stackert, "Pentateuchal Coherence and the Science of Reading," 254).

16 Susan Sontag in her famous essay "Against Interpretation" took aim at all attempts to find meaning in texts. "Interpretation [is] based on the highly dubious theory that a work of art is composed of items of content" (Against Interpretation and Other Essays [New York: Macmillan, 1966], 6). Like Sontag, M. Brettler contends that "coherence is something that the reader creates," that "coherence depends on readers" (M. Z. Brettler, "The 'Coherence' of Ancient Texts," 414, 418). Similarly, E. van Wolde attempts to draw a sharp line between 'cohesion' and 'coherence.' She identifies the first as a feature of texts, the second as a mental construct of readers, which differs from the overlapping qualities of the two in most text-linguistic research (E. van Wolde "The Creation of Coherence," Semeia 81 [1998]: 159-174). We are not suggesting that Brettler and van Wolde agree with Sontag's assertion that all efforts at interpretation violate works of art and should be given up; we merely observe that all three have removed 'meaning' and perforce 'coherence' from the work.

17 "A text does not make sense by itself, but rather by the interaction of text-presented knowledge with people's stored knowledge of the world." (de Beaugrande and Dressler, 6). 
among text users." 18 For the present purposes, we will take "coherence" in a limited sense as referring to the compatibility between constituents of a text. ${ }^{19}$ Within this framework, "coherence" may apply to conceptual connectivity at multiple levels or extents of text, from the proposition, clause, and sentence (microstructural coherence) up to the complete text (macrostructural coherence). ${ }^{20}$ While readers perform an indispensable role in constituting that coherence, coherence cannot be separated from the text as a communicative strategy.

At stake in this debate over the meaning of "coherence"-and in particular the false dichotomy between inherent textual properties and the contribution of the reader within a communication-transaction - is the degree to which the coherence-construal of an individual reader is subject to critical evaluation; i.e. how and to what extent the intuitions and underlying assumptions of readers may be determined by historical analysis to be correct or incorrect, appropriate or inappropriate, valid or invalid, successful or deficient. Given the competing understandings and applications of coherence as a concept, it comes as no surprise that a wide variety of heterogenous phenomena are associated with its establishment or rupture, as we will discuss below.

\subsection{The Relationship to "Unity"}

Notions of "unity" in Hebrew Bible scholarship in particular, add a further layer of misunderstanding. "Unity" and "coherence" sometimes appear to be used interchangeably. Their conflation, however, can again lead to descriptive confusion and obscure fundamental differences in the claims, analytical procedures, methods, and assumptions attending different modes of scholarly reading. This confusion is complicated by the fact that, like the term "coherence," "unity" is taken to mean quite different things in this discussion. As a consequence, one often observes a slippage or lack of conceptual clarity in the application of the term, especially in relation to the notion of "coherence." Three uses of the term "unity" are common in scholarly parlance.

1. Unity as a claim about authorship. For many scholars, the term "unity" is definitionally tied to an historical judgment regarding authorship and production, though the specific model of

${ }^{18}$ Ibid. 6-7; "The process of constituting meaning can be ... described as a continuously progressive selection-directed by the purpose of the speech-from the possibilities of effect and function relating to the given elements whose relevance is known to the speakers; this process results eventually in the individualization of the functions normatively or facultatively given, defined by appropriate categories, and formally determined by their position in the language system, which is directed toward the communicationally relevant, intentional and situational adequacy of what is to be conveyed in a linguistic transaction." (S. J. Schmidt, Bedeutung und Begriff. Zur Fundierung einer sprachphilosophischen Semantik [Braunschweig: Friedr. Vieweg \& Sohn, 1969], 139 cited by Iser, Act of Reading, 183-4)

19 de Beaugrande and Dressler, Introduction, 4; Krause, Textsorten, 57. "The main abstract condition on local coherence is that the complex propositions, expressed by the respective clauses or sentences, denote facts of some possible world that are related, conditionally or by inclusion." (W. Kintsch and T. van Dijk, Strategies of Discourse Comprehension [New York : Academic Press, 1983], 15).

${ }^{20}$ On coherence and structure, see Krause, Textsorten, 57-58 who notes that the concept of coherence stands in tight relationship to the "structuredness" (Strukturierheit) of all texts, and thus that structure and coherence can be seen as two specific ways of looking at the same problem. On macrostructure in relation to coherence, see especially van Dijk, Text and Context: Explorations in the Semantics and Pragmatics of Discourse (London: Longman, 1997), 93-129; 130-63; idem, Some Aspects of Text Grammars (The Hague: Mouton, 1972), 34-129; 130-162; 273-309. See also Kintsch and van Dijk, Strategies of Discourse Comprehension, 79-80; “The themes or macrostructures ... define the global coherence of the discourse. Locally, coherence must be established by the interpretation of relations between sentences, the so-called connection relations" (90). 
authorship - and consequently, the specific features of unity - may vary. ${ }^{21}$ "Unity" can be used strictly to denote the product of singular authorship, i.e. an independent literary unit that is the product of one author, mind, or hand, to the exclusion of composite entities. A "composite text" may thus stand in definitional opposition to a "unified text." 22 Alternatively, "unity" can be used to describe the additive or combinatory work of an author/redactor. By this definition, one might regard a composite text that appears to be the product of multiple authors or to attest to a long compositional development as a "unity" or "unified text," in the sense of displaying a certain compatibility between constituent elements attributable to the intention of a later writer or writers. ${ }^{23}$ Some speak of "secondary" as opposed to "primary" unity, "redactional unity." "24 In such cases, one might meaningfully speak of the "unity" of a complex, multilayered work, without a claim of unitary authorship. Regardless of the exact model of authorship, "unity" as an authorial notion is taken to be either supported or denied on the basis of the reader's experience of in/coherence.

2. Unity as a judgment about textual features. For others, however, "unity" represents an analytic judgment about the internal semantic compatibility or consistency of a text, without expressing commitment to, and thus independent of, any particular conception of authorship or reconstruction of a text's historical development. Such an authorially-agnostic claim of "unity" applied to a text is neither permanently nor necessarily ahistorical, even though deductions about historical production are procedurally bracketed. This understanding of "unity" can be very close to the notion of "coherence"; both may represent statements about the ultimate ("global" or "macrostructural") compatibility of textual constituents. ${ }^{25}$ Often the two are hierarchically ordered, with unity representing the highest-level attribution of coherence.

3. Unity as a phenomenological postulate of all reading. There is a third sense of "unity" that stands in contrast to (1) and (2). In (1) and (2) "unity" represents an a posteriori conclusion or judgment made after having read a text. Here in (3), "unity" is an a priori assumption or anticipation brought to a potential text (any de facto bounded literary unit). "Unity" in this sense is a phenomenological postulate of all reading. ${ }^{26}$ It is what motivates a process of discovery and (re)construction of meaning, enabling the eventual experience of a text as coherent. It is what makes the meaningful experience of any text possible. It is not a judgment about or justification of "unity," understood either as an historical claim about authorship or a claim about how a literary whole hangs together, but an expectation of the mutual compatibility of constituents; that the parts will relate meaningfully to the de facto whole. The quest for "unity" in this foundational, phenomenological sense is already presupposed to some extent in all the approaches discussed under (1) and (2). This expectation of unity can be disappointed,

21 "Unity is a compositional, authorial notion; coherence [by contrast] depends on readers." (Brettler, "Coherence," 418).

${ }^{22}$ As it does, e.g., in Stackert, "Pentateuchal Coherence," 253.

${ }^{23}$ This "compatibility" might be understood in a number of ways: the whole being governed by an overall strategy or plan, for example, or the whole being well-formed, hanging together, or making sense as a whole, and so forth.

${ }^{24}$ Regarding secondary unity versus primary unity, see L. Alonso Schökel, A Manual of Hebrew Poetics (SubBib 11; Rome: Pontificio Istituto Biblico, 1988) 189. "A later writer could take already completed pieces and bring them together skilfully to form a new and complex unity." This is distinct from secondary unity as understood in constructivist readings: see Samely, "Jewish Studies and Reading," 767-68.

25 "Unity is ... only one of the many criteria which we expect an utterance to satisfy if it is to be accepted as well-formed" (Heath, Unity in Greek Poetics, 1, for whom unity and coherence are basically interchangeable).

${ }^{26}$ See esp. the contribution of A. Samely to this volume; cf. idem, "Jewish Studies and Reading," 771-75. 
either temporarily or permanently, by the perception of incoherence. Intuitions about whether and how the expectation of unity can be disappointed permanently (motivating the conclusion that the text is not unified) determine basic distinctions in the varieties of approach to ancient Jewish literature, both critical and non-critical.

\subsection{Differences in approach to Unity and Coherence}

1. Uncritical and Critical Reading. On one side of the spectrum lies uncritical reading as an investment of faith, in which unity is permanently assured and coherence can never be disappointed permanently:

The investment of individuals or social groups in a text's importance can be so high that any internal discontinuities or contradictions it may have are not perceived as such at all, or only experienced as a spur to read more closely and carefully, keeping the assumption of its coherence open ad infinitum. Such an attitude can be found in the hermeneutics of holy text cultures, including those of the Judaism that created the works of Midrash. In such cases the expectation of coherence is never abandoned for good, and therefore incapable of being disappointed. It functions as a dogma of reading. The labours of interpretation, and the expected complexity of devices of meaning, are raised to such heights that simple glaring inconsistencies, contradictions, or repetitions within a text are unlikely to be accepted as such. ${ }^{27}$

Within critical bible reading, on the other hand, the expectation of coherence is always capable of being frustrated permanently. ${ }^{28}$ The license to declare the search for unity a failure and to evaluate further attempts to salvage coherence as historically inappropriate is an essential feature of the post-Enlightenment critical approach toward literature. The availability of this option is a necessary pre-condition for all critical inquiry that understands itself as contributing to the (critical) history and science of literature.

2. Varieties of critical scholarship: diachronic vs. synchronic orientation. Yet a dichotomy between critical and non-critical approaches does not yet suffice to capture the real contours of

${ }^{27}$ Samely et al., Profiling, 23-24.

28 "If a reader assumes an attitude of 'critical' reading, then any initial projection of coherence is constantly kept under review and capable of being rescinded, should evidence to the contrary be encountered. And very importantly, in a critical reading the expectation that the text 'hangs together' is capable of being disappointed for good. The reader is critical because equipped with reasons for deciding to stop looking for unity, and therefore giving up the attempt of understanding the text. This option must always be available to the modern scholar reading ancient sources. This despite the risk of 'missing' the coherence which might have been experienced by ancient readers, or of applying a modern standard of expected coherence which is anachronistic for ancient texts" (Samely et al., Profiling, 23). W. Richter goes further and asserts that the extent of an ancient Israelite literary work can never be assumed as a given on the basis of de facto boundaries, but has to be proven through literarycritical methods. For this reason such methods are procedurally primary. Before anything else can be done, one must pose the question of authorial unity by compiling a list of features that speak against the unity of a text and applying that list to the text to determine what is "original." "Eine als ein Werk überlieferte Größe kann also in sich verschiedene abgeschlossene Werke enthalten, die auf verschiede Autoren zurückgehen und verschiedenen Zeiten angehören. Es sind somit nicht alle Werke israelitischen Literatur unmittelbar gegeben, sondern müssen zum Teil erst erschlossen werden. Diese Arbeit ist nicht in das Belieben jeden Einzelnen gestellt; man kann sie sich nicht ersparen, da sonst jede inhaltliche Exegese in der Luft hängt und historische Bezüge von Aussagen nicht erkannt werden können. Auch wenn wir nicht wüßten, daß es sich im AT so verhält, müßten wir die Frage nach der Einheit stellen; denn wir dürfen sie nicht als einzige Möglichkeit einfach voraussetzen, sondern müssen sie nachweisen" (Richter, Exegese als Literaturwissenschaft, 49). 
difference when it comes to coherence and/or unity in modern Hebrew Bible scholarship. For this, we must also recognize that the broader critical orientation toward the literatures of ancient Judaism includes within its purview diverse methods or approaches, with diverse inclinations toward questions of "unity" and "coherence." Particularly important here are characteristic differences in the focus of engagement with the text between so-called "synchronic" (or "wholistic," or "literary," or "final form") and "diachronic" (or "historical-critical" or "literarycritical") approaches. To take the latter first, diachronic studies tend to be, from a methodological standpoint, oriented toward finding evidence of disunity. ${ }^{29}$ Within the framework of this approach, frustrated attempts at construction of coherence are frequently taken as straightforward evidence of historical disunity. ${ }^{30}$ Such disunity is accounted for historically by appeal to various models of diachronic development. One cannot assume the comprehensibility of ancient works of literature as they presently stand, since any de facto whole may contain various self-contained works produced by diverse authors and belonging to different time periods.

"Synchronic" literary approaches, which are typically (though not necessarily) focused on the extant form(s) of the text, on the other hand, tend to be conceptually oriented toward finding coherence and unity in any particular text, i.e. toward discovering the coherence presumed to exist within the text as an historical object. ${ }^{31}$ Both approaches have their own liabilities and dangers. Those oriented toward unity risk inappropriate harmonization; those oriented toward disunity risk missing historically appropriate strategies of coherence construction that may differ from one's own intuitive expectations. ${ }^{32}$ But they differ not on the question of whether expectations of coherence can be permanently disappointed or unity broken-both are allied in principle against non-critical approaches which would deny that

${ }^{29}$ This is explicit in Richter, Exegese, 49 see note 28 above; cf. e.g., Stackert, "Pentateuchal Coherence," 268.

30 "[C]lassical Literarkritik, with its methodological orientation toward doublets, tensions, textual unevenness, etc., is concentrated from the outset on the possible discovery of incoherence, which is interpreted, as a rule, as a sign of diachronic disunity" (Blum, "Synchronie," 67). Blum rightly emphasizes, however, that incoherence and disunity do not have a one-to-one correspondence, since not every incoherence is due to diachronic disunity, but can represent formulations that turn out not to be contradictory in the end (ellipses, e.g.); divergent but nonetheless tolerated text disturbances; or a deliberate means of unified text formation. On the other hand, diachronically disunified texts are often brought together without notable coherence disturbances (ibid.; for an example see W. Tooman, "Literary Unity, Empirical Models, and the Compatibility of Synchronic and Diachronic Reading," in Ezekiel: Current Debates and Future Directions [eds. W. Tooman and P. Barter; FAT I; Tübingen: Mohr-Siebeck, 2017], 497-512; for additional bibliography see n.79). "One must distinguish between synchronic 'incoherence' and diachronic 'disunity'. The frequent synonymous use of the terms merely covers up and supports a widespread methodological short-circuiting of the process, in which the given incoherence phenomena are interpreted as symptoms of textual diachrony. This is doubtless a possibility; it is, however, only one among others (e.g., that a stylistic incoherence turns out, in a broader frame, not to be a sign of divergence; or to be a consciously introduced artistic device; or it is a feature simply overlooked by the primary author, etc. Equally to beware of is the reverse: a text that presents itself as coherent even under precise analysis is not yet proven thereby to be unified. That point of view would only be possible under the (easily disproved) premise that developmental processes which leave no traces of disruption behind are fundamentally excluded" (E. Blum, "Zwischen Literarkritik und Stilkritik," in Grundfragen der historischen Exegese, 108]).

31 "Synchrone Analysen sind konzeptionell darauf ausgerichtet aufzuspüren, worin die spezifische Kohärenzbildung des spezifischen Textes im Horizont seines semantischen und kommunikativen Gesamtprogramms besteht" (Blum, "Synchronie," 67).

32 Samely et al., Profiling, 23; cf. Blum, "Synchronie," 68. "When incoherencies are assumed to be products of text evolution, this assumption will overwrite or ignore the creative possibilities of deliberate incoherence and close the door to reflection on the different standards of coherence and incoherence between ancient and modern readers. Likewise, when incoherence is assumed to be the deliberate product of literary creativity, it flattens texts into singular voices from singular times robbing them of the deliberate and dynamic exchanges that characterise Traditions-literatur" (Tooman, "Literary Unity," 509). 
possibility as a matter of faith. They differ instead in their view of what constitutes (in)coherence and what may be taken as evidence against unity. ${ }^{33}$

The criteria that count as indications of coherence or its absence depend to some extent on the operative definition of "unity." If "unity" means the product of unitary authorship, to the exclusion of composite entities, then any evidence of composite production or development (which might include not only propositional contradictions, e.g., but also such features as differences in style, language, genre, or outlook) would, as such, demonstrate disunity, regardless of the global compatibility of the constituents. If, on the other hand, "unity" is construed in such a manner as to include composite texts ("redactional" or "secondary unity"), then such texts will be expected to display some of those very features otherwise seen as demonstrating disunity (e.g., divergent style, language, unexplained repetition, redundancies, and other forms of textual unevenness), on analogy perhaps to documentary films today that incorporate archival footage from different eras. The degree to which the notion of "unity" can stretch to accommodate various phenomena of incoherence-whether, indeed, the text can be regarded as readable at all-will depend on prior assumptions about the nature and possibilities of coherence in connection with "unity." Different concepts of "unity" entail different tolerances for "incoherence." The breaking point, the point at which the search for "unity" must be given up, therefore differs among scholars on the basis of their understanding of the nature of the "unity" in question and especially their (usually implicit) coherence expectations.

\section{Part Two: What Makes a Text "Incoherent"?}

\subsection{Standards and their Availability}

This leads to crucial questions about the availability of ancient standards of coherence. ${ }^{34}$ How do we know what should count as evidence of "incoherence" or what constitutes "incompatibility" in the case of ancient literature? This question - the extent to which the standards of coherence appropriate to ancient literature are available or intuitive to modern critics - is a point of crucial difference among scholars. Some argue that ancient standards are readily accessible if not the same as modern standards. Others contend that standards differ across cultures and times and must be learned.

33 Much also depends on the heuristic value, the relative weight, and the procedural ordering of synchronically and diachronically oriented analytic methods. On the methodological priority of synchronic reading, see esp. Samely et al., Profiling, 23-25; and Blum, "Synchronie," 68: "Gerade für eine historische, auf den ,Eigensinn" der Texte gerichtete Exegese müsste sich von daher die methodische Priorität eine synchronen Wahrnehmung, die sich vorbehaltlos und nachhaltig auf den (wie auch immer) gegebenen Text einlässt, von selbst verstehen - sollte man meinen. Freilich ist diese methodische Priorität der synchronen Fragehinsicht nach den Vorstehenden nicht im Sinne eines starren Abfolgeschemas zu verstehen, sondern als methodische Positionierung innerhalb eines komplexen Prozesses der Urteilsbildung, der sich idealiter nach der Art eines weiderholt durchlaufenden Regelkreises vollzieht." Per Richter, on the other hand, Literarkritik must have methodological priority because we cannot assume the boundaries of a "work" (Exegese, 49).

${ }^{34}$ By "standards of coherence" we mean something different than D. McNamara and J. Magliano, who use "standards" to refer to variations in the minimum threshold of comprehension being sought-i.e. the amount of effort given to maintaining coherence, which is "assumed to emerge from factors such as the reader's purpose or goal for reading" rather than different conceptions of what constitutes coherence at all. (D. McNamara and J. Magliano, "Toward a Comprehensive Model of Comprehension," in The Psychology of Learning and Motivation: Vol. 51 [ed. B. Ross; San Diego: Elsevier, 2009], 297-384 at 347). 
1. The standards are already known to critics. Some imply by their argumentation that standards are readily accessible, apparently on the basis of an assumption that standards of (in)coherence are "natural" or universal and remain constant across time-bound to conceptions of the functioning of human rationality and logic, and therefore available to critical thinking. ${ }^{35}$ These assumptions are often tacit and unacknowledged, but they form a fundamental premise of arguments that are put forward about the disunity or incoherence of works in the Hebrew Bible.

For example, according to W. Richter in his handbook on exegetical method, the first step in the literary analysis of the Hebrew Bible must be the compilation of criteria that speak against the unity of a text, followed by the application of those criteria to determine what is "original." The reason for this is again that, in the Hebrew Bible, a traditionally received whole can be made up of a variety of self-contained works from diverse authors and belonging to various times. We therefore cannot presume the unity of a work on the basis of de facto boundaries, but must first work these out. Otherwise, he claims, exegesis remains unhistorical and "hangs in the air," since the historical connection of utterances cannot be recognized. ${ }^{36}$ This procedure, of course, assumes from the outset that the critic has reliable knowledge of the historically appropriate standards of coherence and unity. ${ }^{37}$ This assumption prevails in most of the existing handbooks. ${ }^{38}$

In biblical studies, exegetical handbooks itemize lengthy menus of incoherencies. In his Old Testament Exegesis, for example, Odil Hannes Steck catalogues the following as types of "literary disunity": doublets, multiple transmissions, secondary brackets, tensions in syntax or vocabulary, incomprehensible textual corruptions, differences in manner of speech and style, impossible parallelism, differences in historical background, theological assertions, phrases, and linguistic peculiarities that are not aligned with the (deduced) historical context, tensions and unevenness of content, and elements atypical of a genre. ${ }^{39}$ Richter lists the following criteria: doubling and repetition (on various text-levels: units, segments, sentences, clauses or word groups), tensions (incompatible tensions and contradictions, as well as tensions in personal and place names that differ, as well as syntactical breaks [e.g., unmotivated change in subject]. Other signs of "inauthenticity" are: the appearance or absence of similarly constructed sentences within a segment, and the relative predominance of abstract versus concrete lexemes. ${ }^{40}$ Of course, these phenomena are not limited to biblical literature. Second Temple

${ }^{35}$ As Samely ("Jewish Studies and Reading," 766) points out, there are actually two options: either one assumes "a fundamental cultural resemblance" between the contexts of modern scholars and the ancient text producers, or one assumes that standards are universal; cf. idem, Profiling, 17.

${ }^{36}$ Richter, Exegese als Literaturwissenschaft, 49 (see n. 28 above).

${ }^{37}$ See the similar criticism in J. Berman, Inconsistency in the Torah: Ancient Literary Convention and the Limits of Source Criticism (New York: Oxford University Press, 2017), 275.

38 Although with nuance in Steck, Old Testament Exegesis ( $2^{\text {nd }}$ ed.; trans. J. Nogalski; Atlanta: Scholars, 1998), 47 (=Exegese des Alten Testaments [14 ${ }^{\text {th }}$ ed.; Neukirchen-Vluyn: Neukirchener, 1999], 46).

${ }^{39}$ Steck, Old Testament Exegesis, 9, 39-43, 54-57, 67, 76, 139. Instances of incoherence, for Steck, are indicators of a scribe's attempt to "expand, enlarge, and reorder" an older version of a text (48). It should be noted that Steck carefully considers the limitations inherent in the indicators listed above (esp., 55-57).

${ }^{40}$ Note that, while repetition and redundancy figure prominently in lists of incoherence phenomena in biblical studies, other linguistic studies consider recurrence or redundancy a basic feature of coherence itself. Cf. I. Bellert, who argues for "a necessary (though obviously not sufficient) condition of the coherence of a text consists, roughly speaking, in repetitions" ("On a Condition of the Coherence of Texts," Semiotica 2/4 (1970): 335-63 at 336). Cf. Beekman, Callow, and Kopesec: "In a semantic unit with coherence there will always be redundancy of referential information and/or the recurrence of information belonging to the same semantic or experiential domain. There may be obvious recurrences of referential information through such means as 
literature and Rabbinic literature are also replete with large and small-scale features that modern readers label 'incoherency. ${ }^{41}$

Not all such criteria are to be given equal weight, as the authors of these handbooks emphasize. Some are more determinative than others. To take a particularly clear recent example, consider the following argumentation of J. Baden:

Diversity of language and style, of genre, theme, and theology - none of these reach the tipping point, the moment when it is necessary to search for a literary-historical solution to the problems of the text. None of these render the text unreadable. [...] From the very beginning the impetus for source-critical analysis, the reason that the text was considered so unreadable as to require a literary-historical solution, was always and ever the fact that the narrative, on the level of plot-who, what, when, where, why, and how-is selfcontradictory, repeatedly and incontrovertibly. It is not names for God that render the flood story unreadable, nor was that ever thought to be the case. It is the blatant contradictions in narrative claim at virtually every stage of the story. ${ }^{42}$

Here the breaking point at which the search for unity must be abandoned is considered clear and indisputable. In particular, it is asserted as an incontrovertible fact that the biblical narrative is permanently self-contradictory on the level of plot, and this fact renders the text unreadable, a problem requiring a literary-critical solution. Given genuine differences of competent scholarly opinion regarding most of the textual examples cited, a more cautious representation might be to state that many literary-critical scholars throughout history find various aspects of

repetition, the use of synonyms..., anaphora and cataphora..., overlay structures..., referential parallels, sandwich structures or inclusio..., chiastic structures (abba, abcba, etc.) and other devices" (The Semantic Structure of Written Communication, 21).

${ }^{41}$ See, for example, J. Neusner, Contours of Coherence in Rabbinic Judaism, 2 vols. (JSJSup 97; Leiden and Boston: Brill, 2005), 1: 11, 12-14; Samely et al., Profiling, 26-28, 147-212; K. Keim, Pirqei deRabbi Eliezer: Structure, Coherence, Intertextuality (AJEC 96; Leiden: Brill, 2017), 69, 71, 137-40.

${ }^{42}$ Baden continues: "It is not the differing theological views related to God's position vis-à-vis the world that render Gen 1 and 2 impossible to read as being from a single hand. It is the narratively untenable sequence of events. It is not the differing emphases on priestly and prophetic authority that eliminate the possibility of reading Num 16 as a unified text. It is the utter confusion on the basic level of plot, of who is doing what where and when." [...] "The issue that demands a resolution - that demands a literary resolution in particular-is the issue of plot consistency." (250) [...] "Even scholars who are inclined to isolate the smallest literary units in the Pentateuch inevitably find that those smallest units are narratively coherent - indeed that coherence is one of the defining features of the smallest literary unit. The plot is fundamental; it is irreducible." [...] "Our text is sick, and that illness is exclusively the literary contradictions on the level of plot. This is the level we are operating on." [...] (250) "If it is the contradictions in plot that drive us to the literary-historical analysis of the text-and that is the claim being put forward here - then it is only logical that our literary-historical solutions should also proceed on the basis of resolving those contradictions in plot. This is because, sensibly enough, if we try to divide the text on other grounds - terminological, stylistic, generic, thematic, theological - then we are not actually addressing the basic problem." [...] "Once the plot contradictions are resolved, if we are left with a narratively coherent text, that text can, like any text ancient or modern, accommodate stylistic and thematic and theological complexity. The reverse is not true: a stylistically or thematically or theologically uniform text cannot accommodate plot contradictions." [...] "What makes the Pentateuch unreadable is its thorough-going internally contradictory plot. The analysis that explains that unreadability is, by necessity, grounded in the resolution of those plot contradictions. That is why source criticism exists - that is why anyone ever thought to enter into this sort of analysis hundreds of years ago. And if one does not think the Pentateuch is fundamentally unreadable, then one ought to stop performing elective surgery on it." (J. Baden, "Why is the Pentateuch Unreadable?-Or, Why Are We Doing This Anyway?" in The Formation of the Pentateuch [ed. J. Gertz et al; FAT 111; Tübingen: Mohr Siebeck, 2016, 243-51 at 251). 
the text incompatible with their expectations of coherence on the level of narrative logic. ${ }^{43}$ Such scholars therefore consider it necessary to abandon the attempt to read the text together as an impossible (i.e. historically inappropriate) endeavor. Indeed, the methodological priority granted to the modern scholar's experience of incoherence through the perceived disruption of logical consistency or "narrative flow" is, according to Baden, the only way of "responding authentically" to the text and for the analysis "retaining any degree of objectivity." 44 These same intuitive expectations of coherence are then taken as both warrant and means to critically reconstruct more acceptable unities, texts that conform to expected coherence standards and therefore prove more satisfying and make better sense. That the textual data can be divided and reorganized into more acceptably coherent unities is seen as confirmation of the correctness of the method. 'It works.'

A recent argument of Seth Sanders may also to be categorized under this rubric, insofar as it also assumes standards of coherence as given-though, he argues, not always maintained. ${ }^{45}$ In this piece, Sanders draws attention to the difference between the texts of the Pentateuch and ancient Near Eastern comparanda often seen as providing "empirical models." He argues that the "interwoven" character of the pentateuchal text is distinctive not only by comparison with those texts, ${ }^{46}$ but also in comparison with its own underlying sources. This does not inspire doubt in documentary models. Rather, according to Sanders, it attests to a shift in the dominant "literary values" that took place over the course of the development of Hebrew literature. "For there to be highly coherent strands evident in the Pentateuch that have been interwoven, there needs to be one set of values that created the coherent strand, but a different later set of values that created the incoherent interwoven source." ${ }^{47}$ Whereas the present texts are "radically incoherent" (though, Sanders notes, "still strangely readable" ${ }^{4}$ ) and exemplify the value of "comprehensiveness" by interweaving parallel accounts, their literary precursors (source documents) and successors (later harmonizations, rewritings, and commentaries) exemplify the value of "coherence." Rather than taking the perceived differences as an indication that coherence expectations and the attendant notions of "unity" are themselves variable and contingent, changing along with time and culture, Sanders presents a model of historical development that traces the disappearance and subsequent reemergence of "coherence" as a literary value. In this way, coherence standards are implicitly regarded as

${ }^{43}$ See the formulation of Stackert: "Source-critical analysis of the Pentateuch is a response to frustrated attempts to achieve an intelligible reading of this text as a single, unified work. The procedure of contemporary pentateuchal source criticism thus ever recapitulates its historical origins: stymied efforts to read pentateuchal texts as unified compositions motivate alternative explanations of the texts' geneses and compositional histories, including the identification of sources, strata, redaction, and compilation" ("Pentateuchal Coherence," 253). Such frustrations are not necessarily modern, since they have been found among diverse readers throughout history. See among the contributions of the present volume especially Lyons, "Standards of Cohesion and Coherence: Evidence from Early Readers."

44 "The literary analysis of the Pentateuch is grounded in the basic inability to read the text as a whole, and that inability is not manifested in the variety of themes or style. [...] Instead, what makes the reading of the Pentateuch problematic is its lack of narrative flow, and only by addressing this problem first and foremost can we be responding authentically to the text before us" (J. Baden, The Composition of the Pentateuch: Renewing the Documentary Hypothesis [New Haven: Yale University Press, 2012] 30). "The separation of the literary analysis, on the grounds of narrative flow alone, from all other secondary considerations, be it theme, style, or potential historical setting, must be maintained if the analysis is to retain any degree of objectivity" (ibid., 31).

45 S. Sanders, "What If There Aren't Any Empirical Models for Pentateuchal Criticism?" in Contextualizing Israel's Sacred Writings: Ancient Literacy, Orality, and Literary Production (ed. B. Schmidt; AIL 22; Atlanta: Society of Biblical Literature, 2015) 281-304.

46 "What we never find in Mesopotamian scholarly text-making is what virtually defines the Pentateuch: the interweaving of variant versions of parallel events" (ibid., 295).

${ }^{47}$ Ibid., 299.

${ }^{48}$ Ibid., 298; cf. 301. 
remaining more or less static across time, and therefore naturally available to scholarly intuition and judgment, ${ }^{49}$ even while acknowledging that those standards were, for a time, ignored or suppressed in favor of other literary goals.

Critical procedures and judgments of the kinds represented by the array of scholars described here are predicated upon the assumption that what constitutes an intelligible, comprehensible, or readable whole in antiquity is somehow knowable (or already known) to the critic across historical and cultural distance. ${ }^{50}$ These intuited standards form the basis for diachronic analysis, and are what enables what is considered to be a genuine historical reading and objective reconstruction on the part of the critic, even while acknowledging that traditional readers throughout history have behaved otherwise with respect to the Hebrew Bible. ${ }^{51}$ For many scholars working under these assumptions, traditional attempts at reading for unity are to be categorically distinguished from legitimate historical readings (i.e. readings authentic to the compositional process itself). They are quarantined either under such labels as "midrash" or by characterizing them as the mistaken readings of those prone to natural errors and sloppiness, much like those attested by modern empirical reading studies. ${ }^{52}$

2. Coherence standards are culturally contingent and must be learned. Other critical scholars emphasize instead that conceptions of unity and standards of coherence are culturally contingent and change over time. To the outsider, therefore, the standards must be learned; intuitions and coherence expectations of scholars must remain open to adjustment in accordance with the object of study, if they intend to understand it on its own terms, or to render an historically appropriate judgment. ${ }^{53}$ Among biblical scholars, perhaps the most outspoken proponent of this view in recent years has been Joshua Berman who frames the argument of his Inconsistency in the Torah as a foundational critique of source-critical method in particular. ${ }^{54}$ One may also mention in a similar vein the collection of essays on empirical

49 Thus, Sanders argues, “critical scholars are not being really 'anachronistic' by 'imposing their values' on the biblical text - because the interweaving of two parallel variant plots was not a shared ancient Near Eastern literary value" (ibid., 294).

50 "The forensic diachronic methodology at work here must assume that the standards of coherence of the modern reader are the same as those of the ancient text maker. Otherwise incoherence phenomena could not be interpreted as inadvertent clues to a secondary interference with the original shape of the text. This assumption in turn must be based on one of two beliefs. Either one holds that there is a fundamental cultural resemblance, for example by way of an historical continuity of text expectations, between Jewish antiquity and modern Western scholarly culture; or one believes that the modern-scholarly standards of coherence are universal. Otherwise, that is, if Jewish text makers and readers had different assumptions or habits of text coherence, they may not have seen as incoherent phenomena which we read as incoherent, and thus created texts that contained them from the start" (Samely, "Jewish Studies and Reading," 766).

51 "Yet even if the Pentateuch's incomprehensibility is well established, having been demonstrated repeatedly in its various parts, it is also the case that for much of its history the Pentateuch has been understood as a unified text" (Stackert, "Pentateuchal Coherence," 253).

52 "Compositional analysis requires a cultivated resistance to the human impulse toward coherence, even as this drive was fundamental to the initial identification of sources and strata in the Pentateuch and continues to be so in contemporary compositional analysis" (Stackert, "Pentateuchal Coherence," 268).

53 The danger is not strictly anachronism per se, since some coherence standards intuitive to modern scholars may closely align with those of some ancient authors or periods but not others. See below at $\$ 2.2$ (2).

${ }^{54}$ Berman, Inconsistency in the Torah. The following selections are representative: "The root of the problem...is that scholars have rooted their compositional theories for growth of the biblical text entirely in their own intuition of what constitutes literary unity" (3). Considering "inconsistencies" such as disparity of divine names and the Numeruswechsel, Berman concludes: "These examples serve as a warning flag for scholars looking to parse the text on the basis of their own notions of literary unity. The ancient text is a minefield of literary phenomena that are culturally dependent. The diachronic scholar who treads there based solely on his own modern notions of literary unity risks serious interpretive missteps" (4). "[T] he poetics of the Kadesh Poem demonstrate 
models by Person and Rezetko. ${ }^{55}$ Although not cited by any of these scholars, the historicalmethodological implication of this claim had previously been voiced with particular acuity in the work of Alexander Samely. As Samely states clearly, "The modern scholar has to reckon with the possibility that standards of coherence are historically contingent and that those embodied in the text under consideration are not yet known." ${ }^{56}$ Yet such assertions regarding the cultural and historical contingency of standards of coherence and unity are in no way unique to biblical scholarship, but find support in a wide range of recent studies of diverse cultures

that source critics read ancient texts employing anachronistic notions of consistency, which were not shared by ancient writers. Understanding ancient literary convention requires careful study. The conventions that guided the composition of ancient texts must be learned; they cannot be assumed" (54-55). "When biblicists hypothesize theories of textual development, they do so while situated in a distinctly modern textual culture, and thus are prone to project anachronistic attitudes and practices upon cultures at a great distance from them in time and place. Empirical models offer us methodological controls..." (202). "The irony of this hermeneutic is that it counters the very historicist ethos it seeks to embody. For all historicists of this period, literature is a product of a specific culture situated in a particular and individuated time and place. Conventions of coherence, of communication, and of literary production are all profoundly human constructs, and are themselves historically bound. We might have expected theorists - then and now - to sound a note of caution in adducing theories of textual composition. We might have expected investigators to be take [sic] cognizance of their own situatedness, and to be wary that their own cannons $[\mathrm{sic}]$ of coherence and of literary production could easily be anachronistically superimposed upon the cultures of yore. And yet we see virtually no awareness of these pitfalls in the scholarship of compositional theory of Hebrew scriptures up until quite recently" (222). "This raises the cardinal question: how do we know what constitutes an incongruity? Can we be certain that our notions of narrative consistency are equivalent to those of ancient writers?" (266) "There is no intuitive way to determine what constitutes a fissure in a text from another period and another locale. These sensitivities must be learned, and acquired by careful study. When claims for revision rely on perceived inconsistency or tension in the text and there is no external evidence to corroborate this perception, we may well be imposing modern canons of consistency on these ancient texts, effectively inventing the problem to which revision is the solution. A survey of six primers for source-critical methodology reveals a telling lacuna: all offer detailed examples of how to identify inconsistencies, tensions, and contradictions within the texts of the Torah as telltale signs of revision. But all assume that the modern exegete will be able to correctly flag these, on the basis of his or her own notion of consistency and literary unity. Not one of these primers suggests that competency in the writings of the ancient world is necessary in order to avoid anachronism. Not one cites an example of a seeming inconsistency, but one we know to overlook because of evidence from other ancient texts. I hope this volume has demonstrated the necessity of such controls on our work. Source critics will need to become aware of the situatedness of their own aesthetic sense of literary unity" (275). "Lacking a thorough knowledge of the ancient notions of literary unity, modern scholars perforce, perform their diachronic work in the dark, arriving at conclusions derived exclusively from their own notions of textual cohesion" (276).

${ }^{55}$ R. Person and R. Rezetko, Empirical Models Challenging Biblical Criticism (AIL 25; Atlanta: Society of Biblical Literature, 2016. "However, various contributors directly question the appropriateness of our modern notions of literary unity as a standard for discerning when the literary unity of an ancient text has been compromised." [...] "If our very notion of literary unity is anachronistic, then what we identify as discernible traces based on that anachronistic understanding not only does not provide some sort of objective means for identifying sources and redactional layers but at least in some cases misleads us in that very effort" (29). They reference the contributions of Lemmelijn: "Our modern understanding of logicality need not square with that of the biblical authors and can often be extremely subjective" (132); Lenzi: "[W] hen an argument for revision relies exclusively on some inconsistency, tension, or contradiction within the text and there is no other evidence to corroborate this perception, we run the risk of imposing modern literary expectations on ancient texts and thereby inventing problems to which revision is the solution" (68) (Person and Rezetko, 29-30). See also the recent review by Edward Greenstein of Gertz et al, The Formation of the Pentateuch (in RBL 01/2019), summarizing his earlier articles.

56 Profiling, 25; see also his "Jewish Studies and Reading," 766. "[W]e have no access to readerly intuitions that come from the period of the texts. Our strongest intuitions on what makes sense or what is coherent in a text come from our own time and place..." (ibid., 17). See further the discussion in $\$ 3.2$ below. 
and literatures in the ancient world (e.g., Greece, ${ }^{57}$ Mesopotamia, ${ }^{58}$ in later rabbinic Judaism ${ }^{59}$ ), in the medieval and pre-modern world (e.g., in Islamic tradition ${ }^{60}$ ), as well as in other modern

${ }^{57}$ For ancient Greece, see, e.g., Heath, Unity in Greek Poetics: "If we are to make sense of texts from a remote culture, therefore, we cannot afford to take it for granted that our own expectations are applicable; we should try instead to reconstruct the assumptions, about unity or about any other aspect of a well-formed text, that are appropriate to a text of that kind in that culture. We must become conscious both of the content of our own systems of presupposition and preference, and of their contingent nature; and we must learn to recognize the distance between them and the presuppositions and preferences which determined the composition and original reception of the texts with which we are dealing" (2). "[T]he notion of 'unity' is, as we have stated, subject to historical and cultural change. It follows that if we wish to understand Greek texts we need to reconstruct, among other things, the constraints and ideals of coherence which informed their composition. This is an urgent task. Appeals to an ideal of unity or coherence frequently play a decisive role in exegetical reasoning about ancient literature, but there is little sign that any systematic reconstruction of the relevant aesthetic is being undertakenor even that the need for such a reconstructive effort has been adequately grasped" (3). "Therefore an interpreter sensitive to the historical mutability of taste should wish to explore the possibility that Greek literary practice worked with a concept of unity somewhat different from that at work in modern criticism" (9). See also the classic essay of B. E. Perry, "The Early Greek Capacity for Viewing Things Separately," Transactions and Proceedings of the American Philological Association 68 (1937): 403-27: "If modern habits of mind were the same as those of the pre-socratic Greeks, we should not often err in the interpretation of their literature and thought; but since the psychological differences between them and us are considerable, it frequently happens that modern critics, too much influenced by their own patterns of thought, either find something in early Greek literature that is not there, or else are puzzled and even disappointed by not finding there something which they feel ought to be there. Since this is so, it behoves us as interpreters to keep in view at all times, and in many different connections, those particular characteristics of the early Greek mind which can be recognized as such, and which stand in contrast to modern ways of thinking" (403). "What I have in mind might be further indicated by such captions as "the occasional disregard of logical, moral, or aesthetic sequence in early literature," or "the triumph of parataxis over hypotaxis in thought as well as in grammar," or "immediacy of interest in the early Greek mind," or, more fully still, "the capacity for contemplating only one thing or one aspect of a thing or person at one time, purely for its own interest and without regard to the ulterior implications or associations that an early Greek narrator might indeed be concerned about, but often is not, and that a modern person with his more schematic habits of mind would almost inevitably bring in. I find abundant illustration of this in the language, mythology, religion, and life, as well as in the literature of early Greece" (404).

${ }^{58}$ For just a few examples selected at random of the recent, deep and wide-ranging discussions of the cultural contingencies of cognition, epistemology, rationality, logic, the representation of reality, reasoning strategies, organizational frameworks, literary competence, empirical science (and much more) in ancient Mesopotamia, see M. Van De Mieroop, Philosophy before the Greeks: The Pursuit of Truth in Ancient Babylonia (Princeton: Princeton University Press, 2016); A. Winitzer, Early Mesopotamian Divination Literature: Its Organizational Framework and Generative and Paradigmatic Characteristics (AMD 12; Leiden/Boston: Brill, 2017); J. Borchhardt and E. Bleibtreu, „Aspektiv und Perspektiv in neuassyrischen Flachbild“ in Empirische Dimension Altorientalischer Forschungen (eds. G. Selz and K. Wagensonner; Vienna/Berlin: Lit, 2011), 477526; F. Rochberg, Before Nature: Cuneiform Knowledge and the History of Science (Chicago: University of Chicago Press, 2016) : "Indeed, our construal of cuneiform bodies of knowledge and their associated activities, as well as every aspect of the philosophy of such knowledge - epistemology, reasoning, causality, observation, explanation, and prediction-must be sensitive to its native conceptual grounds, the universe of cuneiform observation, interpretation, and prediction. In this regard, cuneiform knowledge tests our sensitivity to the limit" (14).

59 See, e.g., the reflections of K. Keim: "Textual coherence is a theoretically and culturally problematic concept, in that coherence is to a degree in the eye of the beholder, and different textual cultures may perceive it in different ways. A text which to a reader from one textual culture may appear troublingly lacking in order and completeness, may not bother a reader from another culture from that point of view. In general rabbinic textual culture seems less concerned about coherence according to modern expectations and canons. One can, however, over-stress cultural differences, and it remains legitimate to pose to an ancient text like PRE questions about its unity, orderliness, and boundedness" (Pirqei deRabbi Eliezer, 69). Cf. Samely, Rabbinic Interpretation of Scripture in the Mishnah (Oxford: Oxford University Press, 2002), 4: "[R]abbinic hermeneutics is not a derivative form of our hermeneutics — neither 'philology' nor 'historiography.' The first step towards an adequate historical 
academic fields, such as linguistics or philosophy. ${ }^{61}$ A particularly robust, wide-ranging, and instructive argument of this general point on the basis of the evidence of ancient Egypt, but with relevance for many ancient cultures before the "axial age," is to be found in the work of the Egyptologist Emma Brunner-Traut.

\subsection{Perspectival and Aspectival Representation}

1. Emma Brunner-Traut. In her brilliant study Frühformen des Erkennens, Emma BrunnerTraut draws a basic distinction between traditional Western modes of perception and representation, which she designates "perspectival," and an "aspectival" mode characteristic of ancient cultures such as Egypt. ${ }^{62}$ Beginning with the striking example of the visual arts, Brunner-Traut brings forth an abundance of evidence illustrating a non-perspectival manner of aesthetic representation, arguing that "the method of observation used for Western art cannot be adopted at all for the study of Egyptian art ... [W] cannot understand Egyptian art from the outside, and must instead approach it through its own laws of thought." 63 Artistic representation in ancient Egypt is characterized by the sequential juxtaposition of relatively independent parts, or "aspects," that must be mentally added together to form a whole. ${ }^{64}$ Brunner-Traut cites the formulation of Otto Friedrich Bollnow:

Aspects, particularly when used in the plural, are only individual glimpses, in which a thing is represented from a particular viewpoint. In aspect lies a basic principle of order. Aspect always contains the idea that it is but one among others. Within it lies an instance of needing to be completed. It makes reference to these other aspects. Each is one-sided. In each, certain things emerge in sharper focus than in others and particular connections become clear. None lays claim to completeness. Indeed, how the individual aspects are unified into an overarching whole — and whether they can be unified at all_remain open.

Brunner-Traut adds: "In the Aspective mode of apperception the respective results obtained from the various and diverse aspects remain openly juxtaposed; they are not harmonized in a closed system." ${ }^{65}$ To illustrate, consider the following representations:

understanding of rabbinic interpretation is to offer some resistance to describing it as a variation of what we ourselves do when doing historical scholarship."

60 T. Bauer, Die Kultur der Ambiguität. Eine andere Geschichte des Islams (Berlin: Verlag der Weltreligionen im Insel Verlag, 2011). Our thanks to Alexander Samely for bringing this work to our attention.

61 “...surface structure, style, coherence conditions, themes, discourse types, meanings, and pragmatic and interactional functions are influenced by cultural background. Understanding a discourse according to these cultural strategies hence means that we relate all these levels and dimensions with what we know about the communicative features of the culture of the speaker. Marked (i.e., different culture) cultural strategies typically involve partial understanding. Most hearers or readers will only have limited knowledge about the other culture, so that sometimes guesses must be made about precise word meanings, coherence conditions, implicit beliefs, and pragmatic or interactional functions of the discourse" (Kintsch and van Dijk, Strategies of Discourse Comprehension, 81). On diverse, concurrent "logics" in philosophy, a plurality of logics, see H. Leisegang, Denkformen (Berlin: de Gruyter, 1928).

${ }^{62}$ E. Brunner-Traut, Frühformen des Erkennens am Beispiel Altägyptens (Darmstadt: Wissenschaftliche Buchgesellschaft, 1990). Brunner-Traut's work is established on the foundation laid by H. Schäfer in his Principles of Egyptian Art (ed. E. Brunner-Traut; trans. J. Baines; Oxford: Clarendon, 1974).

${ }^{63}$ Brunner-Traut, "Epilogue-Aspective" in H. Schäfer, Egyptian Art, 421-46 at 422.

${ }^{64}$ Illustrated extensively in Schäfer, Principles of Egyptian Art.

${ }^{65}$ O. F. Bollnow: "Aspekte, zumal in der Mehrzahl gebraucht, sind nur einzelne Anblicke, in denen sich die Sache jeweils von einem bestimmten Gesichtspunkt aus ... darstellt. Im Aspekt liegt ein Ordnungsprinzip ... Im Aspekt ist immer enthalten, daß er einer unter anderen ... ist. Es liegt in ihm ein Moment der Ergänzungsbedürftigkeit. Er verwiest auf diese anderen Aspekte ... Jeder ist einseitig. In jedem treten bestimmte 
To view this image, please refer to the final published version available from the publisher

1. A New Kingdom Egyptian drawing of a compartmented bowl; 2. A contemporary perspectival drawing of the bowl empty, as found; 3 . A contemporary perspectival representation of the bowl as filled; 4. "Reconstruction on the assumption that there were bowls with high divisions between the compartments" ${ }^{\prime 66}$

\footnotetext{
Dinge schärfer hervor als in anderen und werden bestimmte Zusammenhänge deutlich... Keiner erhebt Anspruch auf Vollständigkeit. Ja, wie sich die einzelnen Aspekte zum übergreifenden Ganzen vereinigen und ob sie sich überhaupt vereinigen, bleibt offen.“ To which Brunner-Traut comments „Die unter verschiedenen Aspekten gewonnenen jeweiligen Ergebnisse bleiben bei aspektivischer Apperzeptionsweise offen nebeneinander stehen, werden nicht in einem geschlossenen System harmonisiert" (Frühformen des Erkennens, 5). "According to my definition aspective is exclusively a mode of seeing opposite and in the presence of the object, not forwards or backwards in time, and not moving outside its boundaries. In particular, it does not relate the object, which it has separated in this way in space and time, to the totality of elements that constitute its real existence, and it does not link it functionally to another object, even in a causal relationship. This delimiting mode of seeing is completely orientated towards its object, so that it does not place it in a framework of causality that extends beyond it. The percept seems to remain flat in the plane in which it exists, without reference to what is in front or behind, to past or future. The boundary is the first and last criterion of aspective. By observing each part on its own, separating it from its environment and closing it off, aspective accords it independence. So any change is a leap from one individual, independent form to another, and not, as in perspective, a transition with functional connections which are subject to a more general law [...] In this context it is significant that aspective, as it has no general law that encompasses everything and is raised to the level of abstraction, remains bound to the concrete object and directs its entire attention to it. The delimited part acquires independent values and is declared to be the agent of these values in so far as it has been selected and separated off; for the individual parts are in no way adopted in the work in such a way as to add up precisely and entirely to the whole" ("Epilogue-Aspective," 430).

${ }^{66}$ From Schäfer, Principles of Egyptian Art, 355 fig. 329.
} 
The Egyptian drawing juxtaposes at least two aspects of this multipart object: a pure side view of the bowl and a view of the bowl from straight above. These one-sided aspects are not harmonized, but must be combined - added together - mentally. It is similarly instructive to compare the two portrayals of a pond, seen from directly above, with the persons in profile; and seen from above, with its surrounding trees in profile. ${ }^{67}$

The paratactic juxtaposition of relatively independent parts which additively form unharmonized wholes and characterize Egyptian visual art, Brunner-Traut argues, is found again and again in other facets of Egyptian culture too: in the conception of the state and the ordering of society; in fields of science such as medicine and mathematics; in religion, language, history writing, and law. Found "in short, in the forms of representation and thought of all branches of culture" (70). This leads Brunner-Traut to her central thesis that the artistic distinctives of the ancient Egyptians and related cultures allow one to recognize "with virtual certainty" a basic behavioral mode. Again, this basic mode is that of the step-by-step cognizing of individual, graspable parts of a whole that have only been brought into a bi- or multi-lateral relationship, and from which individual parts the whole is composed in an additive (not synthetic, harmonized, integrated, or amalgamated) manner.

A fine example is the conception of the human body. ${ }^{68}$ Although the body as a singular organism would seem a natural given, it is not understood as such in ancient Egypt. Rather, it is portrayed as a composite of relatively independent parts in the very same manner that arises from the conventions of figural representation in visual art: "Just as a differentiated object is not primarily recognized as a unity from an aspectival view, but rather is construed in a successive manner-i.e., as a juxtaposition of relatively independent parts - so also is the human body not understood as an organism, but as a composite of its members." 69 There is both connection and conflict among the parts.

As with the human body, so also with conceptions of society as a whole. Society is the sum of individuals who are hierarchically oriented in relation to the king. But, like the organs in the human body, people are not understood as a mutually dependent, functional unity, except in the narrow boundaries of immediate family, neighborhood, or village. ${ }^{70}$

Similar deductions are made in the field of Egyptian jurisprudence, in which there was no effort to produce a unified code of conduct: a contradiction-free, abstract articulation of general legal principles. Instead, ancient Egyptian legal texts represent compilations of rules and instructions, wherein individual cases are brought together in an associative manner without ever articulating clear general principles, or even necessarily reasons that are comprehensible and foreseeable for future applications. In such "aspectival" law, cases are juxtaposed even if they contradict one another. "In the place of the generally formulated and thus abstract law of today, among the ancients there was the analogical case, just as there was the paradigm in mathematics" (96).

${ }^{67}$ From Brunner-Traut, Frühformen des Erkennens, 20.

${ }^{68}$ Ibid., 71-81.

${ }^{69}$ Ibid., 71. Brunner-Traut considers a variety of evidence, ranging from vocabulary (the terminology that must stand in for the body, 72) to the treatment and handling of bodily parts in medicinal and burial practice, to the deification of the body, to love poetry, and beyond. This evidence demonstrates that such ideas as "that the body represents an anatomical-physiological functional unity," or "that the organs are mutually dependent upon one another" are "far removed from the Egyptian conception" (73), which instead regards the body as "a number of parts that have been tied up or bound together" [... "a sum of individual parts that can dis-integrate, as they do in a corpse; that can be held together as they should be in mummification, and as they were already 'in the egg"' (72). A similar conception can be seen to underlie the conventions for aesthetic representation of multi-part objects in drawing (see the illustration of washing utensils on 23-24), allowing multiple options for expressing what is visible and invisible.

${ }^{70}$ Ibid., 82-93. 
Egyptian mathematics also operated in an aspectival manner, whereby highly complex problems were reduced to their component parts, parts graspable on their own, and then calculated in the most basic manner of addition. ${ }^{71}$

In the conception of history, too, one observes an aspectival orientation. Ancient Egyptians construe history as a series of successive unities, but decisively not as a single temporal sequence that includes and runs through all time periods. ${ }^{72}$ "In principle, graspable individual events are juxtaposed as independent wholes, without concern for their genesis or mutual interconnection." 73

From all of these forms of cultural knowledge and production, and several others not mentioned here (religion, language, literature), Brunner-Traut concludes that ancient Egyptians (and their intellectual peers) were very capable of thinking logically. The logic associated with aspectival thinking, however, is not the same as Aristotelian logic. ${ }^{74}$ Even if the latter standards are considered superior, one cannot impose them on ancient Egyptian cultural production without serious distortion and misunderstanding. Brunner-Traut also emphasizes along the way that "aspectival" cultures possess different strengths and competencies in comparison with modern Western cultures, among these, e.g., extraordinarily advanced abilities to think in analogical terms. In some of these respects, modern Western thinkers are massively deficient by comparison.

Our purpose here is not to endorse or defend the correctness of Brunner-Traut's description in all its details. We cite her argument here at some length as a powerful illustration of different coherence expectations in relation to the concept of "unity," detailed across many branches of cultural production in ancient Egypt. ${ }^{75}$ It is precisely on the point of the expected relations between part and whole that aspectual and perspectival modes of perception and representation most profoundly differ. That we no longer have automatic access to the 'laws' of Egyptian art, any more than we have intuitive access to their 'laws' of history writing or their juridical theory, is an additional complicating factor. And yet, because there is a gulf between the aspective and

71 Ibid., 129-140; cf. W.F. Reinecke, „Gedanken zur Herkunft der altägyptischen Mathematik“ Orientalische Literaturzeitung 86 (1991), 248-56.

72 "As day follows night...so ancient ruler follows ancient ruler as executor of the same task" (99). "Geschichte war für den gesamten Alten Orient entscheidend Erfüllung von immerseienden mythischen Mustern. Für dieses Geschichtsbild was nicht die Einmaligkeit eines Ereignisses bestimmend, sondern das vorwiegend in der Natur erlebte Spiel der Wiederkehr, die rhythmische Wiederholung eines Typus, eines Modelfalles, orientiert an der Welt der Gestirne oder, wie gesagt, am täglichen Kreislauf der Sonne und wie im Wechsel von Tag und Nacht so an dem der Jahreszeiten, in Ägypten auch an der regelmäßigen Überschwemmung des Nils, allgemein am Werden und Vergehen der Vegetation und des Lebens überhaupt" (100). Here, Brunner-Traut describes Israel as a major outlier in its conception of history. "In Israel ist...eine Geschichtsschreibung gelungen, die sich radikal von jener der damaligen Umwelt absetzt. Die anderen, Sumerer, Akkader, Ägypter, die Phönizier und selbst die am weitesten vorgepreschten Hethiter, sind am mythische Vorstellungsweisen gebunden, die ihnen zwar Annalen eingaben, kleinbogige Darstellungen von Einzelereignissen, Königschriften zumeist, doch keine Geschichte als ein die Zeiten umspannender, durchgehender Verlauf' (Frühformen des Erkennens, 100).

73 Ibid., 156.

74 Ibid., 158; cf. Reinecke, “Gedanken zur Herkunft der altägyptischen Mathematik,” 248 n. 4.

${ }^{75}$ For a similarly wide-ranging treatment, here under the conceptual rubric of "ambiguity" (by which is meant the tolerance for multiple, concurrent, and divergent conceptions within a culture) illustrated in the profoundly interrelated discourses of theology, law, literature, and love poetry within premodern Islam, see Bauer, Die Kultur der Ambiguität. According to Bauer, the cultivation of tolerance toward, and even valorization of, "ambiguity" that can be seen within various forms of cultural expression in premodern Islam stands in strong contrast to the hostility toward ambiguity (Ambiguitätsfeindlichkeit) characteristic of the European Enlightenment and its accompanying processes of rationalization. 
the perspective orientation, the standards of aspective representation have to be recovered inductively as a prelude to a proper appreciation of Egyptian culture.

2. Modern Art. Granting all the differences between the perspectival and aspectival orientations, it is true that some facets of modern Western culture also adopt an aspective orientation that is not unlike Egyptian aspectual representation. This is perhaps most evident in certain movements within the visual arts. ${ }^{76}$ As early as the $1820 \mathrm{~s}$, impressionism was reacting against the subordination of painting to relief sculpture in neo-classical art. Over the next hundred years a new outlook asserted itself, developed by various movements and priorities, counter-movements and rejoinders, all of which rebelled in their own ways against the tyranny of perspective-from-the-artist's-eye. ${ }^{77}$ The first to break with traditional modes of perception were the Fauvist painters like Matisse, but it was the Cubism of Braque and Picasso that finally shattered the connection between natural structures and perceptions and visual representation, initiating what some have labeled a "new cognitive order."

Picasso's Woman with Raised Arms (1936), thought to have been inspired by the photographer Dora Maar and held currently at the Museo Picasso Málaga, offers a salient example of modern aspectival representation.

${ }^{76}$ Cf. Brunner-Traut, Frühformen des Erkennens, 4 for a periodization that includes a kind of "neoaspective" movement in the $20^{\text {th }}$ century.

${ }^{77}$ H. H. Arnason, History of Modern Art: Painting, Sculpture, Architecture (New York: Harry N. Abrams, 1968; 3d ed. 2013), 13-46.

${ }^{78}$ A. Ganteführer-Trier, Cubism (Köln: Taschen, 2004), 6. 
To view this image, please refer to the final published version available from the publisher

The many aspects of this painting — perspectives, lines, planes, colors, foci-cannot be overlaid or harmonized. Some contrast; some contradict; some are ambiguated. The various aspects of the woman's form are viewed from different perspectives. Her eyes and nostrils are viewed square-on, and yet the oval of her face is in three-quarter profile. At the same time, the way her body disappears suggests a point of view from above as she bends over backward. The curved lines and waving hair suggest movement, but the background panels hint that she is prone. (The relationship of her form to the background panels is unspecified, open to any number of interpretations.) The curved and overlaid planes suggest depth, but the representation is also pressed flat by the spare, undetailed features and blocked solid colors. The color scheme, white hands and white crescent set within mainly blue and yellow colorpanels creates an obvious analogy between the woman and the moon with stars set in the sky. That the implicit sky is both day and night wrenches the image out of time. The black lines define everything sharply, except the herbals which blur and blend with the background. All these divergent aspects - square and oblique, still and moving, flat and contoured, woman and sky, day and night, sharp and blurred — cannot be harmonized or amalgamated into a single, perspectival image. They can be added together, but they cannot be synthesized. 
It would be inappropriate to judge cubist art from the standpoint of the logic and conventions of realist (perspectival) art, and yet many early $20^{\text {th }}$ century critics did just that. ${ }^{79}$ A review from 1 May, 1911 in The Craftsman reads: "Picasso does not want to see nature, but how he feels about nature ... But if Picasso is sincerely revealing in his studies the way he feels about nature, it is hard to see why he is not a raving maniac, for anything more disjointed, disconnected, unrelated, unbeautiful than his presentation ... would be difficult to imagine."

Readers of ancient Jewish literature will be familiar with similar criticisms of ancient texts, which are declared "unreadable" because they are disjointed, disconnected, and unrelated. And yet, without access to ancient standards of unity and coherence, this displays no more sensitivity or understanding than did Picasso's unnamed critic. We contend that one could no more declare a non-unified, non-harmonized, additive story-line from the Hebrew Bible to be "unreadable" than one could reasonably declare Picasso's Woman with Upraised Arms "unviewable." Before any judgement can be levied, ancient Jewish standards of (in)coherence must be recovered, in much the same way that Schäfer and Brunner-Traut have done for ancient Egyptian art. Once these standards are recovered, they will surely find analogues in modern culture, like aspectual representation does, but those analogues will always be partial and imperfect.

\section{Part 3. How do we Discern Ancient Standards of (In)coherence?}

If we accept the dual claim that one cannot assume coherence standards to be intuitive or universal nor can one assume the availability of perfect modern analogues to those standards, how can one arrive at appropriate standards in the case of ancient Jewish literature?

\subsection{Empirical Models}

One proposal is that represented by Joshua Berman, who argues that the way forward is to be found in more rigorous attention to ancient Near Eastern literature. ${ }^{80}$ Clearly the study of ancient Near Eastern literature is essential in multiple respects, and such comparisons are invaluable as far as they go. However, one wonders whether this material offers the kind of clear methodological controls and empirical validation that Berman asserts. On the one hand, it is questionable whether there are many genuine comparisons in the ancient world to what is

79 "Picasso has no adherents, and we have to endure the brazenness of those who publicly assert in manifestos to be his adherents, and lead other reckless souls astray." A. Salmon, Paris-Journal, 20 December, 1910.

80 "The root of the problem heretofore, according to this movement, is that scholars have rooted their compositional theories for growth of the biblical text entirely in their own intuition of what constitutes literary unity" (Inconsistency in the Torah, 3) "I seek to question our own notions of consistency and unity in a text, in light of what we discover from the writings of the ancient Near East..." (4) "Canvassing the textual culture of the ancient Near East affords us an awareness of the limitations of our own situatedness: we become aware of authorial and editorial practices that, standing as they do at great remove from our own, sometimes seem to us counterintuitive" (202). 
most characteristic of the compositions of the Hebrew Bible in their received forms. ${ }^{81}$ The ancient Near East lacks prophetic books, to cite just one example. Moreover, scholars are in a similar position when reading, say, ancient Egyptian texts (to take his example of the Kadesh inscriptions of Ramses II) as we are when we read ancient Israelite texts. When confronted with incoherencies, there is no prima facie reason to assume that such texts were written 'in one go' or by one author. That similar incoherence phenomena may appear in the literatures of ancient Egypt and Israel (e.g., the so-called Numeruswechsel) does not itself demonstrate that such phenomena were characteristic of unitary authorship (regardless of whether Egyptologists have subjected the texts to redactional analysis as yet) or even that they were considered unproblematic in antiquity. In point of fact, if we assume that ancient readers and writers had different standards of (in)coherence, why would we assume that they had similar models of composition? ${ }^{82}$ As with any comparative enterprise, one must take into account both continuity and difference. ${ }^{83}$ In sum, properly evaluating the contribution that comparative material can make to the debate entails several layers of complexity.

\subsection{Inductive Text Analysis}

A different approach to the recovery of ancient literary conventions, including standards of (in)coherence, is represented by the TAPJLA project, the "Typology of Anonymous and Pseudepigraphic Jewish Literature of Antiquity, c. 200 BCE to c. 700 CE," conducted at the University of Manchester from 2007-2012. TAPJLA undertook to "describe the literary characteristics of a large number of ancient documents important for the development of ancient Judaism and early Christianity." The object was to draft 'Profiles' of the literary features of 328 works of ancient Jewish literature, providing scholars with detailed descriptions of the texts 'as they are. ${ }^{84}$ One of the major issues raised by the configuration of the TAPJLA project was the issue of (in)coherence. ${ }^{85}$ "Problematic literary structures, like discontinuities, internal contradictions, changes of perspective, and unexplained repetitions, are taken as important features to be noted and defined" (16). TAPJLA, though, deliberately avoided making any judgment about the origins or functions of any literary features, including patterns of (in)coherence. Rather:

${ }^{81}$ E.g., Seth Sanders, "What if there aren't any Empirical Models?" On the question of the value of empirical models, e.g. David M. Carr, "Empirical' Comparison and the Analysis of the Relationship of the Pentateuch and the Former Prophets," in Pentateuch, Hexateuch, or Enneateuch: Identifying Literary Works in Genesis through Kings (eds. T. B. Dozeman, T. Römer, and K. Schmid [Atlanta: SBL, 2011), 73-95; idem., The Formation of the Hebrew Bible (New York: Oxford University Press, 20), 102-49; R. Kratz, "The Analysis of the Pentateuch: An Attempt to Overcome Barriers of Thinking," ZAW 128/4 (2016): 529-61; M. Zahn, "Reexamining Empirical Models: The Case of Exodus 13," in Das Deuteronomium zwischen Pentateuch und deuteronomistischem Geschichtswerk (eds. E. Otto and R. Achenbach; Göttingen: Vandenhoeck \& Ruprecht, 2004), 36-55.

${ }^{82}$ Berman himself sees this (at least at moments): "There is no intuitive way to determine what constitutes a fissure in a text from another period and another locale. These sensitivities must be learned, and acquired by careful study. When claims for revision rely on perceived inconsistency or tension in the text and there is no external evidence to corroborate this perception, we may well be imposing modern canons of consistency on these ancient texts, effectively inventing the problem to which revision is the solution" (Inconsistency, 275).

${ }^{83}$ Profiling, 25.

84 The criteria by which texts were selected for the study are described in Profiling, 7-11. As a generalization, texts had to be (arguably) Jewish, complete (or nearly so), anonymous or pseudepigraphic, from the period c. $200 \mathrm{BCE}-\mathrm{c}$. $700 \mathrm{CE}$, not canonical, and literary. The database of Profiles can be found at: http://literarydatabase.humanities.manchester.ac.uk.

${ }^{85}$ Discussed explicitly in Profiling at 16-18, 20-26, 26-28. 
They [the individual Profiles] provide an explicit, systematic, and comparative description of a text's literary constitution and nothing else. They furnish no historical context, detective work on authorship, diachronic separation of earlier sources, editorship, philological criticism, exploitation for historical information, aesthetic, cultural, or theological appreciation, or religious appropriation. ${ }^{86}$

The reason for taking such a decision had to do with matters of methodological integrity. Modern reading habits profoundly influence academic reading. "Our strongest intuitions on what makes sense or what is coherent in a text come from our own time and place, reader expectations that we learned before becoming scholars and which are reinforced by being scholars and writing academically." $" 87$ And yet, there is no apparent reason to assume that modern reading and ancient reading are identical. Modern readers have no access to readerly intuitions from ancient periods and cultures. As such, "there is a prima facie need for supplementing or educating our intuitions of coherence." 88 The only way to acquire culturally appropriate intuitions, while simultaneously avoiding the historical questions that attend comparative, empirical research, is to "scrutinize the large amount of available evidence of what texts are actually like." 89 In this way, scholars can build up temporally and culturally appropriate intuitions, even if those intuitions are imperfect.

Alexander Samely, the principle investigator on TAPJLA, describes this as learning the "ways of the text":

For the critical reader who is not familiar with the ways of the text by virtue of shared cultural intuitions, the text itself has to become the primary evidence for its ways and its methods of coherence. And for the text to be able to testify to its own manner of textuality, the evidence of its boundaries is indispensable. The modern scholar has to reckon with the possibility that standards of coherence are historically contingent and that those embodied in the text under consideration are not yet known. ${ }^{90}$

What this requires, initially anyway, is an upfront investment in the coherence of the texts under consideration. Alexander Samely again:

For a limited period all close reading, including that of ancient sources by the modern critical scholar, has to invest up front in the coherence of the text. For the reader, in particular the reader encountering a text across a historical and cultural depth yet to be plumbed, must first acquire sufficient experience in the ways of the text before she or he has the 'right', so to speak, to stop looking for a text's unity. The ways of the text cannot even be explored adequately without first investing in the text's unity ... So the ways of the text do not become visible without the expectation that it forms an internally complex but bounded whole, without investment in coherence. This is true in particular for texts whose ways are unfamiliar to the reader - the situation of the modern scholar reading ancient sources. The alternative, namely giving up on coherence too soon, is hard to remedy. Just as the expectation of coherence can be self-fulfilling for uncritical readers,

${ }^{86}$ Ibid., 12

${ }^{87}$ Ibid., 17

${ }^{88}$ Ibid., 28

89 Ibid.

${ }^{90}$ Again, and crucially: this is the precise inversion of the methodological claim of W. Richter (see n. 28 above); cf. Blum, "Synchronie," 67. 
so the expectation of incoherence can be self-fulfilling for readers who give up too early. ${ }^{91}$

It is essential to say that the approach proposed here does not entail any commitment to the unity or coherence of any variety of ancient Jewish literature. That one must begin with an investment in a text's coherence does not mean that one will conclude that the texts are coherent. Expecting texts to make sense does not mean that those expectations cannot be frustrated decisively. An upfront investment in the coherence of the texts is a necessary starting point, nothing more; but it remains methodologically necessary.

\subsection{Proposal}

A precondition of a better understanding of ancient Jewish literatures is the ability to transcend our intuitive and learned coherence assumptions when encountering texts from those other cultures and times. We propose that the approach that says or assumes that coherence standards are unchanging is untenable and unscientific. Further, so-called 'empirical models' are not a cure-all because we are in the same position of ignorance when reading and evaluating comparative evidence from antiquity as we are when reading Hebrew Bible and other ancient Jewish literatures. We are not making any assertion about what the standards of (in)coherence might have been in Jewish antiquity. We are asserting that we cannot assume that we know them, and that the only way forward is investing up front in a text's unity while undertaking a comprehensive analysis of the literature itself, learning the 'ways of the text.' Only then will we be in a position to offer educated, culturally appropriate deductions about the standards of (in)coherence at play in ancient Jewish literature.

\section{Part 4. Moving Forward}

Obviously, we have offered nothing in this essay except an anatomy of issues and a proposal regarding the best way forward as we see it. Before next steps can be taken, it is essential to establish the relevant questions, questions that require further exploration and research. Many but not all of these questions reflect our interest in establishing the 'ways of the text.' Some are second-order questions that look further afield to raise comparative and diachronic issues, issues relevant to a wider historical understanding of ancient Jewish literature. These questions can only be properly approached, we would assert, after an inductive, comprehensive analysis of the ancient Jewish literature itself, unprejudiced by our own standards and expectations of coherence.

1. Methodological questions. What types of evidence might reveal something about ancient

${ }^{91}$ Ibid., 24-25. He continues: "The text's boundaries must be allowed to define and limit the meaning options, in particular for the reader who is unfamiliar with the ways of the text. The factuality of boundaries is what permits the text to make sense in unexpected ways, but only if the reader takes them seriously ... For the critical reader who is not familiar with the ways of the text by virtue of shared cultural intuitions, the text itself has to become the primary evidence for its ways and its methods of coherence. And for the text to be able to testify to its own manner of textuality, the evidence of its boundaries is indispensable. The modern scholar has to reckon with the possibility that standards of coherence are historically contingent and that those embodied in the text under consideration are not yet known." [...] "In the absence of reliable access to the text's historical context, the factuality of what is inside it and what is absent from it, where it starts and where it ends, may be the text's only defence against anachronistic expectations on the side of the modern scholarly reader" (ibid.). 
standards of literary (in)coherence? Is it fruitful to distinguish between expectations of coherence and tolerances of incoherence? That is, might certain types or occasions of incoherence be tolerated by ancient readers and writers while, simultaneously, being perceived to be incoherent? How might this be established? In what ways are the dominant methods of text-analysis practiced by modern scholars in alignment or nonalignment with ancient standards? When (if ever) is it reasonable to conclude that ancient Jewish writers had similar standards of textual (in)coherence to those of their predecessors, contemporaries, and successors in their own or neighboring cultures?

2. Diachronic/Temporal questions: What can be said about the historical development of conceptions of (in)coherence within ancient Jewish literature and traced across its various cultural contexts? What continuities and what differences can be observed over time and space? (Perhaps differences are traceable through comparison of different iterations of a single tradition, different texts with overlapping subject matter, diachronically distinct textual levels within a single composite document, the literatures of different language groups, or a work and its composition-external reception, including translation?)

3. Content/Subject Matter: Do coherence expectations differ according to the topics or concepts handled or according to how ideas are configured or presented? For example, are there differences in standards of (in)coherence between different literary types (narrative versus sentence literature, versus prophetic oracles, versus prayers, versus treatises, etc.)?

4. Nature and Scope of Compositional Activity: Are there different coherence expectations or tolerances associated with different types of compositional activity (e.g., aggregation versus deliberate and planned composition, writing versus rewriting, source text versus translation, etc.)? Is it useful to distinguish between the coherence expectations appropriate to larger and smaller text-segments within a single work? If so, what precisely is the nature of such a hierarchy, and how does it relate to axis 2 and axis 3 above?

Considering the differences in time, place, and circumstance in which these texts were produced, a perfectly consistent account that can be systematized will prove impossible (or would be false if it were possible). Our hope is that these questions can serve as a starting point, to help us move toward a flexible model for understanding better the standards of (in)coherence in Jewish antiquity. 